\title{
In Search of Mitochondrial Mechanisms: Interfield Excursions between Cell Biology and Biochemistry
}

\author{
WILLIAM BECHTEL \\ Department of Philosophy \\ University of California, San Diego \\ Campus Box 0119 \\ 9500 Gilman Drive \\ La Jolla, CA 92093-0119 \\ USA \\ E-mail: bechtel@mechanism.ucsd.edu
}

\author{
ADELE ABRAHAMSEN \\ Center for Research in Language \\ University of California, San Diego \\ Campus Box 0526 \\ 9500 Gilman Drive \\ La Jolla, CA 92093-0526 \\ USA \\ E-mail:abrahamsen@crl.ucsd.edu
}

\begin{abstract}
Developing models of biological mechanisms, such as those involved in respiration in cells, often requires collaborative effort drawing upon techniques developed and information generated in different disciplines. Biochemists in the early decades of the 20 th century uncovered all but the most elusive chemical operations involved in cellular respiration, but were unable to align the reaction pathways with particular structures in the cell. During the period 1940-1965 cell biology was emerging as a new discipline and made distinctive contributions to understanding the role of the mitochondrion and its component parts in cellular respiration. In particular, by developing techniques for localizing enzymes or enzyme systems in specific cellular components, cell biologists provided crucial information about the organized structures in which the biochemical reactions occurred. Although the idea that biochemical operations are intimately related to and depend on cell structures was at odds with the then-dominant emphasis on systems of soluble enzymes in biochemistry, a reconceptualization of energetic processes in the 1960s and 1970s made it clear why cell structure was critical to the biochemical account. This paper examines how numerous excursions between biochemistry and cell biology contributed a new understanding of the mechanism of cellular respiration.
\end{abstract}

Keywords: biochemistry, cell biology, cell fractionation, cellular respiration, decomposition, discipline, electron microscopy, interdisciplinary, interfield theories, localization, mechanistic explanation, metabolism, mitochondria 


\section{Introduction}

The rise of cell biology as a new field of science in the post World War II period got much of its impetus from pioneering discoveries involving the mitochondrion that brought together previously separate lines of inquiry. Prior to 1940, cytologists sought a structural decomposition of the cell but were limited by the resolution of light microscopes. For example, they could identify mitochondria as rod-shaped components within the cytoplasm, but could not see down to the next level of structure. Biochemists contributed to a functional decomposition of the cell by targeting the molecular mechanisms for achieving cellular functions. By 1943 they had achieved a partial account of the biochemical systems responsible for cellular respiration, the process of breaking down the digestive products of proteins, fats, and carbohydrates and harvesting their energy. However, they were approaching the limits of their methods. Moreover, neither cytologists nor biochemists were attempting to bridge the two orders of magnitude between the smallest structures accessible to cytologists and the molecular level of biochemical reactions. Cell biologists stepped into this terra incognita. They contributed new methods that extended the structural decomposition to lower levels, advanced the functional decomposition, and most important, made it possible to align these accounts by localizing systems of reactions within parts of the cell at multiple levels.

Interfield excursions between biochemistry and cell biology played a crucial role during the period 1940-1965. Scientists in these fields jointly achieved an interdisciplinary account in which each respiratory mechanism was situated in the appropriate cell structure, and the component reactions and their organization had been specified to varying degrees of adequacy. At this point further development of the account became once again primarily a task for biochemists, now regularly employing the research tools originally brought to the enterprise by cell biologists. By the end of the 1970s they had a detailed account of each system of reactions and, as an important legacy of the influence of cell biology, could specify at a molecular level how each system was woven into the structures of the mitochondrion. 
The history of research on cellular respiration within the period 19401965 provides an advantageous case for investigating how fields interact, including the construction of what Darden and Maull call interfield theories. ${ }^{1}$ A number of fields were involved at least peripherally in this history, each with its own mission, methods, domain of inquiry, and institutional structures. For tractability, we will not discuss contributions from such fields as physiology, histology, and physical chemistry. Instead, we will focus on the three fields most directly involved: cytology (for its historical role as the field in which mitochondria were first observed and discussed), biochemistry, and cell biology. We begin with brief histories of cytology and biochemistry through the early 1940s and then turn to a more detailed examination of cell biology's emergence and relationship with biochemistry through 1965 .

\section{Cytology and Early Observations of Mitochondria in the 19th Century}

Cytology historically was the field that sought to identify subcellular structures and, to the extent possible, link structures to general functions such as respiration, secretion, or cell replication. Though scientists had used light microscopes to observe cells since 1665, cytology emerged as a field in the 1830s under the impetus of the new achromatic lens. By mid-century all plants and animals were thought to be composed of cells that, despite variations in detail and appearance, had a common material (protoplasm) and basic structure (cell body, nucleus, nucleolus, and perhaps a cell wall or membrane). There were hints of smaller subcellular structures known generically as organelles, but sightings were inconsistent and inconclusive until new fixatives, stains, and Ernst Abbe's apochromatic lens greatly enhanced contrast and detail around the 1870s. The first cytology journal ( $\mathrm{La}$ Cellule) began publication in 1884 and provided a forum for the rising field's triumphs - such as observing mitosis and other stages of cell division - as well as its controversies.

Of greatest relevance here, Richard Altmann ${ }^{2}$ and Carl Benda ${ }^{3}$ each argued for the existence of a kind of organelle that sometimes appeared

1 According to Darden and Maull, 1977, an interfield theory sets out and explains one or more of several types of relations. The interfield theory that emerged for cellular respiration exemplifies their relations of structure-function, part-whole, and physical location-process. Also see Bechtel, 1984, for analysis of an interfield theory relating vitamins to coenzymes.

\footnotetext{
2 Altmann, 1890.

3 Benda, 1899.
} 
threadlike and at other times more granular. Benda named them mitochondria, from the Greek words for thread and granule, to capture his claim that quite different images were produced by exemplars with the same long, narrow shape depending on the angle at which each happened to be sliced. If so, some of the bafflingly diverse forms within the microscopic image of a single cell could be subsumed under a single category. By the turn of the century, it was generally accepted that the mitochondrion was not an artifact of cytological methods but a genuine organelle with multiple tokens within each cell.

Cytologists also knew that such key functions as breaking down, synthesizing, transporting, and discarding materials were realized by biochemical reactions within cells. Occasionally the methods at their disposal hinted at the functions of particular subcellular structures, as when Michaelis showed that Janus Green, a dye sensitive to the oxidation-reduction reactions that play a key role in cellular respiration, was selective for mitochondria. ${ }^{4}$ However, the first four decades of the 20th century brought only incremental improvement in cytologists' tools and therefore in their understanding of subcellular structures. The modest additions to knowledge of mitochondria involved their shape, distribution, chemical composition, and response to changes in the intracellular environment. Cytology gradually became less a scientific frontier and more an applied area within medicine, but its unrealized aspiration - identifying the structural components of cells at multiple levels - would become part of the mission of cell biology.

\section{Biochemistry and Cellular Respiration through the Early 1940s}

Biochemistry is the field that has the goal and some means of determining the systems of chemical reactions that realize cellular functions. Around the time that cytology was losing steam at the beginning of the 20th century, biochemistry emerged as the newest incarnation of a long tradition of chemical investigation of biological materials. In the early 19th century it was already known that carbohydrates and other organic compounds are comprised of a surprisingly small number of elements (primarily carbon, hydrogen, oxygen, and nitrogen). Further work yielded increased knowledge of these compounds and the discovery of catalysts. By the end of that century there were distinct journals for physiological chemists, who focused on the compounds and reactions involved in physiological processes, and organic chemists, who made

4 Michaelis, 1899. 
headway by focusing on simpler compounds. Physiological chemists knew the sites at which such metabolically important structures as hydroxyl, carboxyl, and amino groups could link to a carbon backbone, ${ }^{5}$ and had succeeded in localizing respiration as an intracellular process. ${ }^{6}$ However, there was disagreement about the extent to which such processes could be understood in terms of ordinary chemical reactions stimulated by catalysts. Many scientists took the issue as settled when Eduard Buchner announced in 1897 that he had achieved fermentation (the conversion of glucose to alcohol) by adding sugar to press juice made by adding water to ground yeast and then filtering it under pressure. He concluded that the key factor was not cell structure, but rather a soluble protein in the press juice that he called zymase. ${ }^{7}$

With zymase as a prototype enzyme, biochemistry launched itself as the discipline in which the chemicals of life are studied in the absence of life. Experiments on solubilized cell contents brought rapidly expanding knowledge of enzyme-catalyzed biochemical reactions and the discovery of another class of soluble proteins - coenzymes - that played an essential, though poorly understood, role. Biochemists took it as their mission to identify each biochemical reaction in terms of its substrate and product, its particular enzyme, its place in the system of reactions that realized a given physiological function, and any coenzyme involved. They also attended to how reactions were organized; for example, in intermediary metabolism the earliest reactions generate intermediate substances that then themselves undergo reactions. ${ }^{8}$ Among the new journals that sprang up as biochemists rallied around their new identity were Journal of Biological Chemistry in the U.S. in 1905, Biochemische Zeitschrift in Germany in 1906, and the Biochemical Journal in Great Britain in 1906.

Emphasis on techniques that destroyed cell structure and solubilized the contents not only differentiated biochemistry from the older tradition of physiological chemistry, but also helped keep it at arm's length from the science that studied such structures, cytology. These techniques can be briefly characterized as follows: After obtaining the desired tissue, a mortar and pestle (later a Waring blender) would be used to break the plasma membrane that bound its cells. Particles and debris were removed by means of filtering or low-speed centrifugation. Often an

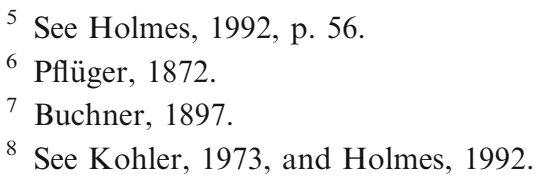


attempt would be made to purify the solution (e.g., via precipitation or dialysis) so as to isolate a particular enzyme of interest. Whatever the details of obtaining the cell preparation, biochemists then intervened in various ways in order to identify operations at the molecular level. For example, they could add a suspected intermediate and see whether this produced a reaction. Or once a reaction had been achieved, they might add a poison and determine which chemical product accumulated. These methods were highly successful over time in isolating enzymes that catalyzed reactions, including many of those involved in cellular respiration. However, it had been known since the early 20th century that some important enzymes were insoluble. Even if particles were deliberately left in the cell preparation, the enzymes in them could not be segregated from each other and were inaccessible to the usual intervention and assay techniques. In these cases biochemists had to settle for assaying enzyme systems rather than individual enzymes. The Warburg manometer was used for decades to measure the amount of oxygen, carbon dioxide, or other gas consumed or produced in the reactions catalyzed by a particular system of enzymes, including those within mitochondria.

Several distinct investigative streams emerged, each focusing on a different biochemical system involved in cellular respiration. Figure 1 summarizes the outcome of this work circa 1943. Systems that receive digestive products (glucose, fatty acids, or amino acids) and further break them down to a common product are indicated on the left. The first to be understood was glycolysis, in which each molecule of glucose yields two of pyruvic acid via a chain of ten reactions involving phosphorylated intermediates (collapsed to five reactions in Figure 1). Since these are the same reactions as in fermentation, they could be investigated in yeast juice or other solubilized cell-free extracts using techniques derived from those of Buchner. It took about 35 years to progress from his zymase proposal to the full system. ${ }^{9}$ The release of two hydrogen atoms in one of the reactions is important because their energy is utilized in the respiratory chain. An additional dehydrogenation occurs in the transitional step between glycolysis and the citric acid cycle. In the early 1940s it was known that this step produced hydrogen, carbon dioxide, and an important three-carbon compound that was not identified until 1951-1952 as acetyl-CoA. Such gaps in knowledge

${ }^{9}$ The main scheme of what came to be known as the Embden-Meyerhof pathway was put forward by Embden, Deuticke, and Kraft, 1933 and filled in by Meyerhof and Kiesslling, 1936. For historical discussion, see Bechtel, 1986. 


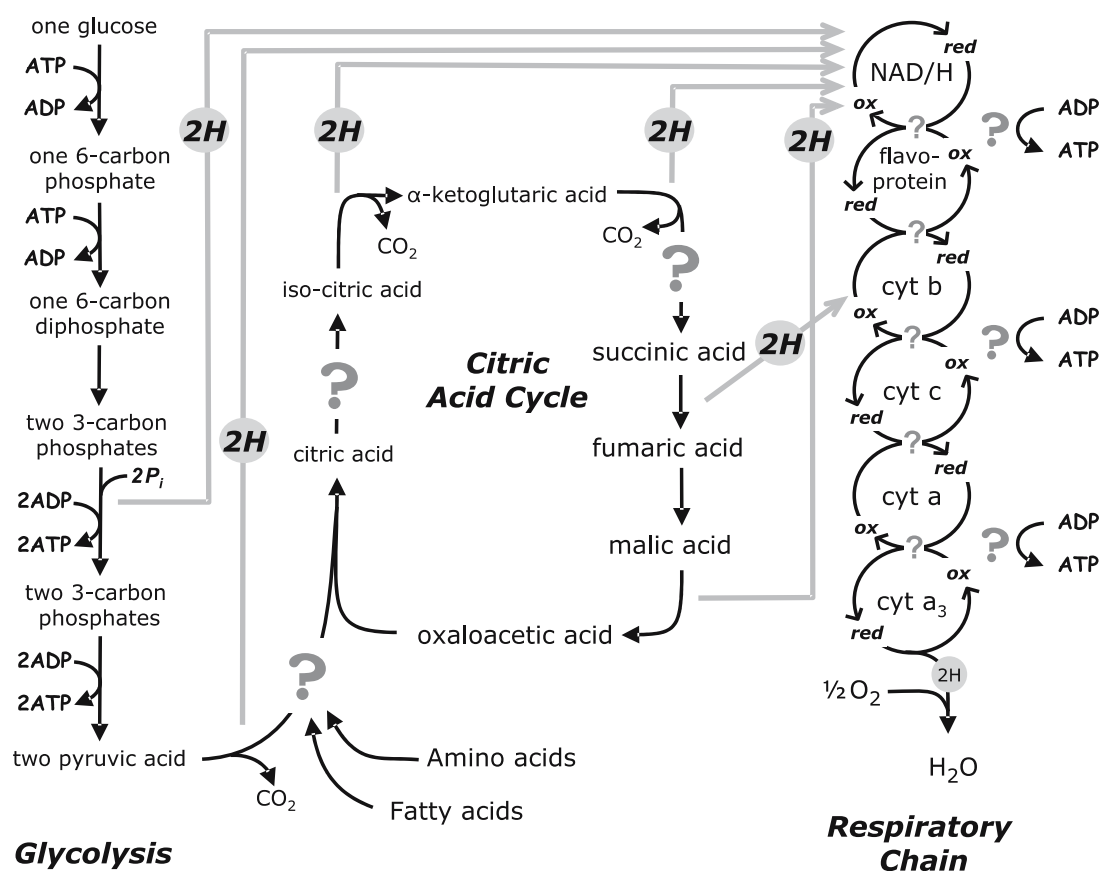

Figure 1. Major reactions identified by the early 1940s in the enzyme systems for cellular respiration, beginning with glycolysis. In breaking down complex molecules from food, catabolic reactions release energy that is either stored in ATP by substrate-level phosphorylation (lower left) or transferred in a chain of oxidationreduction reactions (path of $2 \mathrm{H}$ ) and stored in ATP by oxidative phosphorylation (far right). See text for further explanation.

regarding reactions or their products are flagged by question marks in Figure $1 .^{10}$

The systems for breaking down fatty acids and amino acids were less well understood than glycolysis and are not detailed in Figure 1. However, it was known that the three-carbon compound that was the common product of all three catabolic systems was taken up by the citric acid cycle. Like glycolysis, this system involves intermediary

${ }^{10}$ Most substances in Figure 1 are labeled as in the early 1940s. However, the figure is simplified by omitting the names of enzymes; summarizing glycolysis using descriptive names for key intermediates; and using the current terms NAD/NADH for what were initially called coenzyme I/II and then DPN/TPN. The flavoproteins FAD and FMN had been distinguished, but with confusion regarding which one figured in which pathways. $2 H$ would later be explicitly unpacked into $2 e-$ and $2 \mathrm{H}+$ and their fates separately traced. The use of coupled curved arcs to illustrate the reduction-oxidation reactions of the respiratory chain is adapted from Baldwin, 1947. 
metabolism: a basic backbone of reactions in which the product of one reaction serves as substrate for the next. Unlike glycolysis, its basic backbone has a cyclic rather than linear organization. A few of the constituent reactions were being investigated already in the first decade of the new biochemistry, and by 1925 a chain of six reactions and the possibility that it closed into a cycle had been proposed. ${ }^{11}$ The reactions succinic acid $\rightarrow$ fumaric acid $\rightarrow$ malic acid were especially interesting, because the account that found acceptance ${ }^{12}$ was one of the earliest applications of Heinrich Wieland's important reconstrual of oxidation as the removal of hydrogen (not the addition of oxygen) and reduction as the addition of hydrogen (not the removal of oxygen). This brought into biochemistry such terminology as hydrogen donator (or donor), hydrogen acceptor, dehydrogenation, and - capturing his further claim that reduction of one substance was necessarily coupled to oxidation of another - redox reaction. Also relevant was biochemists' practice of assigning names to enzymes in accord with the assumption that they were reaction-specific, even when they could not be isolated for study.

Thus, the 1916 account held that a putative succino-dehydrogenase oxidized succinic acid to fumaric acid, and that fumarase (in the presence of water) then hydrated the fumaric acid to yield malic acid. Of the six reactions in the 1925 account, these and one other were retained by Hans Krebs and William Johnson in their landmark 1937 account of the citric acid cycle (also known as the tricarboxylic acid or Krebs cycle). ${ }^{13}$ They proposed that the still-unidentified three-carbon compound condensed with oxaloacetic acid to form citric acid and that a particular series of reactions ensued. Some released hydrogen, and the last regenerated oxaloacetic acid from malic acid, thus closing the cycle so that it could be repeated indefinitely. Though some parts remained to be worked out, this is essentially the account still in use today.

The main function served by the citric acid cycle is getting energy that is bound up in the common product of the catabolic pathways into a form in which it can be utilized in the last two, closely linked systems: the respiratory chain and oxidative phosphorylation. The methods developed for cell-free extracts were of little use here, so research on these systems took place somewhat outside the mainstream of biochemistry. The final step - the consumption of oxygen in a reaction that produced water - was the first to be investigated. Otto Warburg

11 See Holmes, 1992, pp. 22-24.

12 Thunberg, 1916, advanced this account within the framework offered by Wieland, 1913.

${ }^{13}$ Krebs and Johnson, 1937. 
(Wieland's great rival) focused on the enzyme catalyzing this reaction, which he called Atsmungferment. ${ }^{14}$ Then in 1925 David Keilin announced the discovery of "cytochrome ... an intracellular respiratory pigment composed of three haemochromogen-like components (cytochromes $a, b$ and $c$ ) which undergo reversible oxidation and reduction within living cells." ${ }^{, 15}$ Each component was itself composed of a protein with an iron-porphyrin prosthetic (active) group, and the reversible reactions were localized in the iron atoms. By 1939 Keilin, with Edward Hartree, also had distinguished component $a_{3}$ from $a$ and characterized the four components as forming "a highly active catalytic system which by utilizing molecular oxygen can easily oxidize to water certain hydrogen atoms in the substrate molecules activated by specific dehydrogenase systems." $"$ They named the enzyme catalyzing this oxidation cytochrome oxidase and identified it with Warburg's Atmungsferment (based, for example, on their identical absorption spectra). Keilin and Hartree also tentatively identified it with component $a_{3}$ in particular, but commented that the $b-c-a-a_{3}$ system could be regarded as either three hydrogen carriers plus an enzyme or as a four-component system of enzymes.

Keilin's work on the respiratory chain provided the initial sketch of a mechanism for transporting hydrogen atoms from substrates stepwise down an energy gradient to a final reaction with oxygen. Its sequence of coupled, reversible oxidation-reduction (redox) reactions brought to light a distinctive form of biological organization that complemented the intermediary architectures of glycolysis (linear) and the citric acid cycle (cyclic). Keilin focused on the cytochromes, but during the 1930s Warburg made a cluster of major discoveries about the first part of the chain - that is, what happened to the hydrogen atoms released in intermediary metabolism $(2 \mathrm{H}$ in Figure 1$)$. Working with Walter Christian, he found that the hydrogen acceptors were new classes of compounds that engaged in redox reactions, accepting and then themselves donating hydrogen. Specifically, in 1932 they

\footnotetext{
${ }^{14}$ Warburg, 1925. Note that Warburg did not himself make use of the notion of enzyme system. He persisted in using the older term ferment rather than enzyme and did not recognize Atsmungferment as part of a larger system. At the time he thought it activated oxygen to directly remove hydrogen from such compounds as succinic acid and combine with it to form water. For more detail on Warburg, see Kohler, 1973 and Krebs and Schmid, 1981; for more detail on the conflict between Warburg and Wieland and other developments in this period, see Fruton, 1972 and Holmes, 1991.

15 This compact characterization of Keilin, 1925, is from a summary provided in Keilin's 1966 book, The History of Cell Respiration in Cytochrome. See Keilin, 1966, p. 149.

16 Keilin and Hartree, 1939, pp. 189-190.
} 
identified the first flavoprotein; each member of this class has a reversibly oxidizable flavin nucleotide as its prosthetic group or coenzyme. ${ }^{17}$ Between 1933 and 1936 they discovered the pyridine nucleotides NAD and NADH, another class of reversibly oxidizable coenzymes that they called coenzyme I and II. ${ }^{18}$ By the early 1940s it was generally agreed that each dehydrogenase in glycolysis and in the citric acid cycle (except succino-dehydrogenase) had either NAD or $\mathrm{NADH}$ as its coenzyme. It was further thought that these coenzymes, once reduced, in turn reduced a flavoprotein, which reduced cytochrome $b$, which reduced cytochrome $c$, and so forth, with each donator being oxidized as its acceptor was reduced. These proposals captured the respiratory chain in broad outline, but question marks at each redox coupling (hydrogen handoff) in Figure 1 indicate missing compounds or uncertainties regarding exactly which reactions were coupled.

What happens to the energy released by the transport of hydrogen down the respiratory chain? In the 1930s it was found to be temporarily stored in energy-rich phosphate bonds $(\sim \mathrm{P})^{19}$ by adding a third phosphate group to adenosine diphosphate (ADP), yielding adenosine triphosphate (ATP). There are two ways this happens in cellular respiration. Substrate-level phosphorylation, exemplified in the last two major steps of glycolysis in Figure 1, couples ATP synthesis to ordinary catabolic reactions. Oxidative phosphorylation, a much more efficient process that captures the lion's share of energy from the original glucose molecule, couples ATP synthesis to the redox reactions of the respiratory chain. Evidence about this complex process was sparse in the early 1940s, but an estimate that three molecules of ATP were formed for each oxygen molecule reduced to water suggested that three different links of the respiratory chain were directly involved. ${ }^{20}$ ATP

17 Warburg and Christian, 1932. The prosthetic group of this "yellow enzyme" is flavin mononucleotide (FMN). Warburg and Christian, 1938, discovered flavin adenine dinucleotide (FAD) and raised the possibility than FMN was an experimental artifact. It took many years to sort out that FMN follows coenzymes I and II in the respiratory chain, whereas FAD is the coenzyme of succinic dehydrogenase. It was also found that hydrogen (electrons) from both FAD and FMN enter a common chain at a new component, coenzyme Q, probably prior to the perennially troublesome cytochrome $b$. Cytochrome $c_{1}$ was inserted following $b$. See Wainio, 1970, pp. 77-86.

18 Warburg and Christian, 1936.

19 This term, and an influential integration of the work to date, were offered by Lipmann, 1941.

${ }^{20}$ Ochoa, 1943. Later Britton Chance developed a technique using spectrography to determine which reactions in the electron transport chain were accompanied by phosphorylation. See Chance and Williams, 1956. 
synthesis via oxidative phosphorylation is therefore shown at three parts of the respiratory chain (right edge of Figure 1). The question marks indicate that almost nothing was known about the mechanism or its coupling to electron transport. However, there was "a growing conviction that ATP plays a central role as a funneling agent" of chemical energy in cellular respiration ${ }^{21}$ and a nascent appreciation that it carried a universal energy currency that could be spent by breaking its phosphate bonds. Glycolysis illustrated this well - it begins by spending energy in two ATP $\rightarrow$ ADP reactions and ends by banking twice as much energy via four ADP $\rightarrow$ ATP reactions.

\section{The Creation of Cell Biology}

Cell biology emerged when a few biologists initiated progress towards interfield theories that integrated the traditional concerns of cytologists with those of biochemists by localizing particular reactions or reaction pathways in the appropriate cellular structures. Their ability to do this rested on adding two new techniques to the existing ones: cell fractionation (1930s-40s) permitted isolation of biochemical reactions within particular subcellular structures, and electron microscopy (1950s) verified those structures and enabled the discovery of yet smaller ones. ${ }^{22}$ From varied biological backgrounds including cytology, histology, anatomy, physiology, and cancer research, these scientists were prompted by their mission to team up with biochemists. The resulting research and interfield theories were so successful that they gave rise to an enduring field. The term cell biology gained currency when laboratories began using and identifying with it in the 1950s, including one at the Rockefeller Institute that plays a central role in the case discussed here.

${ }^{21}$ Fruton, 1972, p. 375. For details underlying our very brief synopses, see Fruton's broader treatment of ATP and respiratory chain coenzymes on pp. 334-387. See also the retrospective discussion by one of the primary investigators, Kalckar, 1974.

${ }^{22}$ In this paper we are focusing on research on the mitochondrion, but this was just one of the cell organelles targeted by the pioneers of cell biology. Two of the central researchers discussed below, Porter and Palade, also discovered the endoplasmic reticulum and the ribosomes attached to it, key structures for protein synthesis. Palade also was instrumental in determining the role of the Golgi apparatus in preparing cell secretions. Christian de Duve identified the lysosome as an organelle containing hydrolytic enzymes that functions to digest aged organelles as well as substances brought into the cell. See Bechtel, 2006. 
Cell biologists' ambitious agenda was reflected in the initial name in 1956 - The Journal of Biophysical and Biochemical Cytology - of what 6 years later became The Journal of Cell Biology. The revised name reflected a certain distancing from the limited methods and results of traditional cytology as well as an intention to encompass all perspectives on cells. They especially made a point of including biochemists on the editorial board. The American Society for Cell Biology, established in 1960, similarly sought to include biochemists in their membership and leadership. ${ }^{23}$ Biochemists already had their own institutional structures, however, and only a small number chose to identify themselves as cell biologists. Accordingly, the relationship evolved into interfield excursions rather than the formation of one fully integrated field. Over time, similar relationships with such fields as genetics and developmental biology became at least as important to cell biology. For the fertile period of 1940-1965, though, it is the multiple excursions between cell biology and biochemistry that provide an ideal case for investigating how fields interact. We begin with a development that, in retrospect, was the first step towards the creation of cell biology as a new field.

\section{Cell Biologists Introduce Fractionation Studies of Mitochondria (1934-1948)}

Although there were suggestions in the cytological literature that the mitochondrion figured in cellular respiration, biochemists in the 1920s and 1930s generally made no note of that fact. Many of the biochemical reactions involved in cellular respiration were identified from cell-free extracts with great success, but others were elusive - they somehow relied on the particulate matter that usually was filtered out in the process of making the preparation. Lehninger drolly characterized such particles as "a nuisance." ${ }^{24}$ It turned out that they were important cellular components, but at the time there was a gulf between what cytologists knew about such components and what biochemists knew about the much finer-grained chemical reactions that took place within them.

To segregate chemical compounds active in a particular subcellular structure from others, a new technique - cell fractionation - was required. It had roots in the practice of centrifuging ruptured cells as a means of isolating their nuclei. High-speed ultracentrifuges became

${ }^{23}$ For an account of the founding of these institutions, see Bechtel, 2006, chapter 7. On two occasions in the initial decade of the Society, two biochemists were nominated to compete for president to ensure than a biochemist would hold that office.

${ }^{24}$ Lehninger, 1951. 
available in the 1920s, and by the mid-1930s a few biologists were using them to isolate smaller particulate components of cells. Then Albert Claude, beginning in 1937, took the further steps that established cell fractionation as a major new technique in which multiple rounds of centrifuging yielded distinct cell fractions that could be studied biochemically. ${ }^{25}$ This was not Claude's original intent. Working in a cancer laboratory at The Rockefeller Institute a year after receiving his M.D. in Liège, he was trying to purify what he thought was the active agent for Rous chicken sarcoma. He learned that sedimentation during each round of centrifuging produced a particulate fraction and a remaining fluid (the supernatant) that retained relatively lightweight particles. These would then sediment on the next round using a higher centrifugation speed.

Claude adopted a procedure that yielded four fractions. First, low-speed centrifuging isolated the heaviest particles, particularly nuclei. Second, high-speed centrifuging of the supernatant remaining from the first step isolated a "large-granule" fraction, which Claude initially misinterpreted but by 1943 identified as predominantly mitochondria. Third, higher-speed centrifuging of the supernatant remaining from the second step isolated a "small-granule" fraction. The fourth fraction was the supernatant remaining after removal of the small granules. Claude initially hoped that the small granules were the active sarcoma agent, but abandoned this idea when he found them in normal cells as well. He suggested calling them microsomes. Too small to be viewed using light microscopes, these were a new addition to the inventory of cell structures known to cytologists.

His unexpected findings led Claude to redirect his attention from cancer cells to cells in general. ${ }^{26}$ For each fraction of interest, he wanted not only to identify the part of the intact cell that corresponded to its particles, but also the enzyme systems operational in it. He could then infer that a particular enzyme system was situated within a particular subcellular component. That is, biochemical accounts emphasizing function - enzymes and the molecular substrates on which they oper-

${ }^{25}$ For more detail on early uses of the ultracentrifuge, including pioneering work by Bensley, Ledington and Gye as well as Claude's steps and missteps, see Bechtel, 2006, chapter 5 .

${ }^{26}$ Rheinberger, 1995 , p. 61 comments on the manner in which these developments transformed Claude's research: "What had been the tumor agent, 'was' now a cytoplasmic particle. The new scientific object arose and began to be delineated first as an intrusion, then as a supplement within the confines of the old cancer research system. Shortly after, it took over and transformed the system itself." See also Rheinberger, 1997. 
ated to achieve cellular respiration - would be linked with cytological accounts emphasizing cell structure.

This ambitious research program would contribute directly to the emergence of cell biology as an interfield enterprise. To identify the enzyme systems operating within mitochondria, Claude joined forces with two biochemists at the Rockefeller Institute, Rollin Hotchkiss and George Hogeboom. They had the necessary skills to employ the biochemical technique for quantifying the activity of enzyme systems localized in particulate matter. Using a Warburg manometer, a substrate such as succinic acid salt was supplied to particles suspended in an appropriate medium and the resulting rate of oxygen gas uptake was measured. The greater the rate, the greater was the activity of the enzymes along the pathway from the substrate to the ultimate reaction in which oxygen and hydrogen yield water. This technique did not allow for probing the activity of each individual enzyme, as was possible for enzymes operating freely in aqueous parts of the cell rather than bound together in insoluble particles. However, with the introduction of cell fractionation, at least biochemists could now focus the Warburg technique on a particular particulate fraction to determine, for example, which systems of enzymes were present and active within mitochondria versus microsomes or other particles.

Supplying succinic acid salt to a suspension of the large granule fraction provided a measure for succinoxidase, the enzyme system that catalyzes the reduction-oxidation (redox) reactions that carry hydrogen along the pathway from succinic acid through the cytochromes to $\mathrm{H}_{2} \mathrm{O}$ (see Figure 1). Claude, Hogeboom, and Hotchkiss did not specifically investigate the pathways from other citric acid cycle intermediates through the cytochromes. However, they did supply cytochrome $c$ to obtain a separate measure for cytochrome oxidase, which they regarded as an enzyme system responsible for the last few redox reactions culminating in the production of water. Finding both of the tested enzyme systems active and acceptably specific to the large-granule fraction, they suggested "that the cytochrome oxidase and succinoxidase systems... are entirely localized in the so called large granules.",27

The other key task was to show conclusively that the large granules were mitochondria rather than some other cell structure. For this Hogeboom joined forces with two other scientists who had recently joined the laboratory at Rockefeller: Walter Schneider (also a biochemist) and George Palade (a Romanian M.D. with a background in physiology and anatomy who became a key figure in establishing cell

${ }^{27}$ Hogeboom, Claude and Hotchkiss, 1946, p. 626. 
biology as a new field). They found that the large granules retained the size, rodlike shape, and staining properties of mitochondria if they were suspended in a $0.88 \mathrm{M}$ sucrose medium, which became the standard in this field.

This result established that the fraction was in fact mitochondrial, and when it was taken together with the result showing that activity of two crucial oxidative enzyme systems was localized in the fraction, the case was secured for a bolder conclusion than that of 1946. They now said: "The mitochondrion can therefore be considered as a complicated functional unit possessing two of the most important respiratory enzyme systems of the cell." ${ }^{28}$ Since respiration was regarded as the key to unleashing the energy in food, Claude further ventured in his 1948 Harvey Lecture that "mitochondria may possibly be considered as the real power plants of the cell." ${ }^{29}$ - a metaphor so apt that, stripped of the cautionary verbiage, it became an enduring part of the lexicon biologists use in introducing cell biology to a wider audience.

\section{Biochemists Adopt Cell Fractionation and Localize Additional Enzyme Systems in Mitochondria (1948-1951)}

The localization of two key respiratory mechanisms in mitochondria provided the first linkages for building an interfield theory connecting biochemistry to cytological structure. It also helped explain why Keilin and Hartree's cytochrome preparations always contained particulates. Could this line of research be pushed back to include any of the enzyme systems that get respiration started by catabolizing glucose, fatty acids or amino acids? The first affirmative answer came from the biochemical laboratory of Albert Lehninger at University of Chicago. Applying the new Rockefeller techniques, he and Eugene Kennedy localized the fatty acid oxidase system in a mitochondrial fraction of liver cells. ${ }^{30}$ Their investigations were extensive enough to localize in mitochondria not only enzymes specific to fatty acid metabolism, but also those essential to oxidative phosphorylation (as indicated by ATP synthesis), the citric acid cycle, and all of the pathways into and through the respiratory chain - including but not limited to cytochrome oxidase and succinoxidase. As an important negative finding, the reactions of glycolysis were catalyzed by the supernatant, not the mitochondrial fraction or

${ }^{28}$ Hogeboom, Schneider and Palade, 1948, p. 360.

29 Claude, 1948, p. 137.

${ }^{30}$ Kennedy and Lehninger, 1949. 
other fractions with insoluble particulate components of the cell. This placed glycolysis in the aqueous part of the cytoplasm (the cytosol) rather than in the organelles of the cytoplasm (mitochondria, microsomes, etc.). The product of glycolysis, pyruvic acid, would therefore need to be transported into mitochondria to be converted into the substance (now identified as acetyl-CoA) that enters the citric acid cycle.

Lehninger was one of the first to glimpse a biochemistry that encompassed insoluble, membrane-bound enzymes as well as soluble enzymes. Noting that the rate of metabolism was difficult to explain by diffusion of intermediates in solution, and that the enzyme systems involved in fatty acid metabolism could not be reconstituted from solubilized liver tissue, he concluded that

The mitochondrion may therefore not be considered merely as a sac containing a solution of soluble oxidative enzymes but as an organized structure with an insoluble matrix in which are embedded the individual catalytically active proteins making up the complex enzymatic machinery of oxidation and phosphorylation.... It would appear that these carrier proteins must be fixed in space so that the hemes are juxtaposed, increasing the probability of fruitful collision, or that special mechanisms must exist to allow passage of electrons through the protein moieties. ${ }^{31}$

That is, Lehninger's excursion into the emerging field of cell biology for its technique of cell fractionation and goal of using that technique to localize biochemical pathways in cellular structures had taken him further than expected - to the recognition that at least one kind of cellular structure, the mitochondrion, did not simply provide a locale for biochemical reactions but organized them by holding key macromolecules in place.

Ideas like this were appealing to another biochemist, David Green. In 1948, he proposed that the primary mechanisms of aerobic respiration (including fatty acid oxidation, citric acid cycle, respiratory chain, and oxidative phosphorylation) involved a single, physically structured system of enzymes he called the cyclophorase system. He envisioned each enzyme as bound to a structure in its own advantageous position and noted that such organization "confers properties on the various enzymes which they may not necessarily enjoy when separated from the complex and isolated as single enzymes." 32 When he became aware of Kennedy and Lehninger's results, Green saw the similarity to his own and embraced their localization of the system in the mitochondrion. As he later wrote:

31 Lehninger, 1951, p. 12.

32 Green, 1951, p. 18. 
"The mitochondrion and the cyclophorase system thus turned out to be the structural and functional sides of the same unit." 33 Some of Green's claims went considerably beyond available evidence and had limited uptake among other biochemists. Nonetheless, Lehninger's and Green's general suspicion that mitochondria somehow held key molecules in place proved prescient eventually, when the enzymes of the respiratory chain were found to be embedded in the inner membrane of the mitochondrion. Before that could happen, the inner membrane itself had to be discovered.

\section{Cell Biologists Use Electron Microscopy to Reveal Submitochondrial Structure (1945-1955)}

The second major innovation giving rise to cell biology - use of the electron microscope to obtain high-resolution images - made it possible to explore the internal structure of mitochondria. Claude took some initial steps in this direction during the same period he was refining the cell fractionation technique. His collaborators were Ernest Fullam, an electron microscopist at Interchemical Laboratory, and Keith Porter, a young researcher in the Rockefeller laboratory who was to become a leader in using electron microscopy (EM) to study cells and cell fractions. In 1945 they reported the first, primitive electron micrographs of the large and small granules obtained via cell fractionation ${ }^{34}$ and also of whole cells in which mitochondrial filaments were visible. ${ }^{35}$ It would be left to others to pursue the internal structure of mitochondria due to two developments. First, Porter became more interested in the lace-like reticulum (soon to become known as the endoplasmic reticulum), on which particles related to Claude's microsomes were identified. Second, Claude returned to Belgium in 1949 as director of an institute at Université Libre de Bruxelles. This essentially brought to a close his remarkable role in establishing cell biology as a new discipline - work for which he shared a Nobel Prize with Palade and de Duve in 1974.

Electron microscopy began to realize its promise as a tool for discovery when technical advances were achieved at Rockefeller in the early 1950s: a new buffered osmium fixative developed by Palade ${ }^{36}$ and a microtome capable of producing extremely thin slices of cells developed by Porter with instrument maker Joseph Blum. ${ }^{37}$ Palade used these

\footnotetext{
33 Green, 1957-1958, p. 178.

34 Claude and Fullam, 1945.

35 Porter, Claude and Fullam, 1945.

36 Palade, 1952.

37 Porter and Blum, 1953.
} 


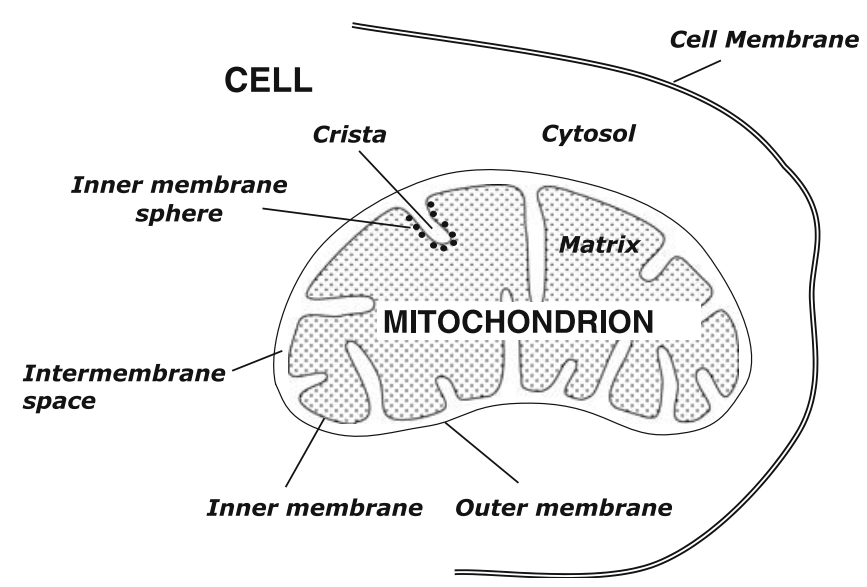

Figure 2 Structural decomposition of the cell emphasizing the mitochondrion (other organelles not shown). An imaginary pinprick would traverse the cell membrane, aqueous cytosol, mitochondrial outer membrane, inter-membrane space, inner membrane with cristae (identified in 1952), inner membrane spheres (identified in 1962), and matrix.

techniques to obtain micrographs that revealed fine structure within the mitochondrion: a "system of parallel, regularly spaced ridges that protrude from the inside surface of the membrane towards the interior" 38 and oriented "more or less perpendicular to the long axis of the mitochondrion." ${ }^{39} \mathrm{He}$ called the ridges cristae mitochondriales and observed that they had a central layer, 8 to $10 \mathrm{~m} \mu$ thick, enclosed by two thinner, denser layers. ${ }^{40}$

Palade's discovery of the cristae led mitochondrial research to a new, deeper level. Most directly, he had offered the first glimpse of a structural decomposition of the mitochondrion. Soon thereafter, improved EM images would convince him that the mitochondrion had a double membrane and that it was the inner membrane whose infoldings formed the cristae. Within 10 years, as discussed in a later section, it was also known that they were studded with small spheres. (See Figure 2 for a schematic illustration.) Less directly, Palade's

\footnotetext{
38 Palade, 1952, p. 428.

39 Palade, 1952, p. 432.

${ }^{40}$ Fritiof Sjöstrand at Sweden's Karolinska Institutet had his own very high resolution micrographs of what he called ultrastructure as early as 1952. However, he argued that Palade's cristae were actually separate structures within mitochondria, not infoldings of the mitochondrial membrane. For him, the appearance of contact was an artifact of Palade's fixation technique. See Sjöstrand, 1955.
} 
findings raised the prospect of localizing the enzyme systems of oxidative metabolism not simply in the mitochondrion but in the appropriate component part. Palade suggested the cristae:

... it has been postulated that the enzymes involved in such processes are maintained in a 'definite spatial relationship' (Schneider and Hogeboom, '51) inside the organelles. It may be assumed that they are arranged in the proper order in linear series or chains - a disposition comparable in design and efficiency to an industrial assembly line. Such enzymatic chains have to be built at least partially in the solid framework of the mitochondrion because some of the component enzymes, namely succinic acid dehydrogenase (succinoxydase) and cytochrome $c$ oxidase, are known to be insoluble and structure-bound.... it may reasonably be assumed that the mitochondrial matrix is fluid and that the membrane and the ridges represent the solid framework. In the present state of our knowledge, the internal ridges of the mitochondria appear as the most probable location for the postulated enzyme chains. ${ }^{41}$

\section{Biochemists Localize Enzyme Systems in Submitochondrial Structures (1955-1965)}

Palade had offered plausible arguments for localizing certain key mechanisms of cellular respiration in the cristae. To obtain direct evidence, the fractionation technique would need to be deployed at a lower level of structure - targeting mitochondria rather than cells - and coordinated with biochemical and microscopy techniques. In the mid1950s Lehninger and Green each developed effective procedures for subfractionation and also collaborated with electron microscopists to complete a four-step procedure in which it was necessary to:

\footnotetext{
41 Palade, 1952, pp. 438-439. Sjöstrand, 1955, again took exception to Palade's interpretations, commenting dismissively that "speculations regarding the functional significance of these structures ... [should] be reserved for very informal discussions or private contemplation" (p. 29). For more detail on the disagreements between Palade and Sjöstrand see Rasmussen, 1995, 1997; Bechtel, 2006, Chapter 6. Rasmussen argues that the disagreements were due in part to very different conceptions of the status of electron microscopy research. Whereas Palade's objectives were to develop electron microscopy in a manner that would support collaboration with biochemistry, Sjöstrand was more focused on developing exact quantitative measurements of cell structures that he thought would provide an independent way to answer biochemical questions.
} 
- Rupture the intact mitochondria that comprise the particles in the large granule fraction;

- Ultracentrifuge the ruptured mitochondria to obtain subfractions composed of components with different sedimentation rates;

- Use biochemical assay methods to link particular enzyme systems to particular subfractions;

- Use electron microscopy to determine whether any of the subfractions might be associated with the cristae.

Green focused on a subfraction containing what he called electron transport particles (ETP). His biochemical work, measuring oxygen uptake when ETPs were supplied with NAD or succinic acid, showed that these particles contained the components of the respiratory chain. Leaving behind earlier terminology, in which these reactions were characterized as harvesting energy from pairs of hydrogen atoms, Green made more explicit the understanding that it was pairs of electrons, dissociated from protons, that were transported down an energy gradient. ${ }^{42}$ Though his term electron transport particle applied only to a particular kind of fractionation product, the respiratory chain - from flavoprotein through cytochrome $\mathrm{a}_{3}$ - would soon come to be labeled in term of its function as the electron transport chain.

The final step was to associate ETPs with the cristae, in accord with Palade's prediction. Although these finger-shaped "ridges" were visually striking in electron micrographs of intact mitochondria, each was an infolding of the inner membrane and it was this membrane material that mattered biochemically. It would be sufficient for the purpose if electron micrographs of the ETP fraction revealed inner membrane fragments. In collaboration with electron microscopist Hans Ris, ${ }^{43}$ Green concluded that ETPs were small inner membrane fragments, each of which had closed up to form a round vesicle. The fact that they could transport electrons when supplied with NAD or succcinic acid suggested that flavoprotein and cytochromes were available at the outer surface of the vesicles. Green contrasted ETPs to larger, well-formed fragments in a different subfraction that apparently also contained NAD and the dyhydrogenases for several citric acid cycle intermediates, since they could transport electrons when supplied with those intermediates. He called these fragments phosphorylating electron transport particles (PETP) because they could also carry out oxidative phosphorylation,

\footnotetext{
42 An earlier example can be found in Oppenheimer and Stern, 1939, pp. 8-14.

${ }^{43}$ Ziegler et al., 1958.
} 
apparently using an enzyme that was absent or closed up in the interior of ETPs.

While Green focused most of his research on electron transport, Lehninger worked with Cecil Cooper to pin down "enzymatic details" that would contribute to "resolving the mechanism of oxidative phosphorylation'. 44 They showed that their own phosphorylating membrane fragments from rat liver could catalyze both oxidative phosphorylation and electron transport when supplied with $\mathrm{D}$ - $\beta$-hydroxybutyrate (a compound specific to fatty acid metabolism) or succinic acid (the citric acid cycle intermediate whose pathway bypasses NAD). Electron transport was evidenced by oxygen uptake, and oxidative phosphorylation by ATP synthesis using radioactive phosphate as a tracer. These fragments apparently were composed of flavoprotein and cytochromes with little if any NAD: unlike the mitochondrial fraction that Lehninger had studied with Kennedy, or Green's PETP, they did not catalyze oxidations or intermediary reactions when supplied with citric acid cycle intermediates for which NAD is the electron-transporting coenzyme.

Lehninger and Cooper mentioned micrographs that identified the fragments as arising largely from mitochondrial membranes, particularly the inner membrane, but did not pursue EM to the same extent as Green and Ris. They did show that exposure to sonic vibrations prior to centrifugation greatly reduced the size of the fragments (as indicated by a slower sedimentation rate) but not their efficacy. From this, Lehninger and Cooper concluded that the fragments were themselves composed of repetitions of an elementary respiratory assembly. Each such assembly would be capable of both electron transport and oxidative phosphorylation, but knowledge of the latter process remained elusive.

\section{Structure and Function Meet at the Molecular Level: Inner Membrane Spheres (1962-1965)}

In 1962, cell biologist Humberto Fernández-Morán, using a newly developed negative staining technique for electron microscopy, discovered $85 \AA$ spherical knobs on $50 \AA$ stalks projecting from the cristae into the mitochondrial matrix. ${ }^{45}$ These are indicated on one of the cristae in Figure 2 as tiny black spots. Green seized upon this finding, proposing that an entire electron transport chain was localized in each these inner membrane spheres. Then Fernández-Morán obtained more

\footnotetext{
44 Lehninger et al., 1958, p. 450.

45 Fernández-Morán, 1962.
} 
detailed micrographs and collaborated with Green in a modified proposal that put cytochromes $a / a_{3}$ in the sphere, cytochromes $b$ and $c_{1}$ in the stalk, and flavoproteins FMN and FAD in the inner membrane. ${ }^{46}$ Both of these speculative proposals were wide off the mark. ${ }^{47}$

It was research on submitochondrial particles by another biochemist, Efraim Racker, that yielded the correct structure-function localization. In the late 1950s and early 1960s, before the spherical structures were known, Racker and his collaborators were seeking a finer-grained account of oxidative phosphorylation than had been achieved by Lehninger and Cooper in their studies of phosphorylating membrane fragments. They employed a strategy in which mitochondria were broken with glass beads in a vacuum and then fractionated, yielding a red-brown, gelatinous residue or particulate fraction that could not carry out phosphorylation unless the supernatant was re-introduced. Since this indicated that the supernatant contained a substance crucially involved in coupling phosphorylation to the oxidation of substrates (via the electron transport chain), they set about purifying the supernatant to isolate it. In a series of papers, the most important in 1960, they called this substance coupling factor $F_{l}$ and also found some additional factors that played an auxiliary role. At this point Racker followed up on a suggestion first advanced by Henry Lardy and Conrad Elvehjem ${ }^{48}$ that phosphorylation might be the inverse of the hydrolysis of ATP, which had been attributed to the enzyme ATPase. He and his collaborators found that $F_{1}$ indeed could hydrolyze ATP (i.e., could catalyze the reaction with water that cleaves ATP into ADP and $\mathrm{P}_{\mathrm{i}}$ ). At a temperature around $0^{\circ} \mathrm{C}$ the rate of activity was identical for hydrolysis and for phosphorylation. He therefore concluded that the same enzyme, ATPase, was responsible for both activities and identified it with $\mathrm{F}_{1}{ }^{49}$

After Fernández-Morán discovered inner membrane spheres on the cristae, Racker collaborated with Donald Parsons and Britton Chance in 1965 in examining a preparation of pure $F_{1}$ in an electron microscope. ${ }^{50}$

\footnotetext{
46 Fernández-Morán et al., 1964.

47 This way of grouping components of the electron transport chain was a contribution of several members of Green's team (Hatefi, Haavik and Griffiths, 1962), and endured since it was based on good evidence regarding which components worked together in complexes. In contrast, there was no direct evidence for either of the localization proposals and a strong argument against the first one: Lehninger, 1964, p. 226 , had calculated that the weight of the respiratory assembly was one to two orders of magnitude greater than that of an inner membrane sphere.

48 Lardy and Elvehjem, 1945.

49 See Penefsky et al., 1960; Pullman et al., 1960; Racker, 1965, chapter 13.

${ }^{50}$ Racker et al., 1965; see also Racker, 1968.
} 
They observed spheres that were similar in size and appearance to those of Fernández-Morán. They had shown that if the native spheres were removed from preparations of the inner membrane, the altered membranes were still capable of electron transport but not of oxidative phosphorylation. They further established that if $F_{1}$ were then added to these altered preparations, the characteristic appearance (membrane lined with spheres) was restored. When some of the other coupling factors they had isolated were added to the restored preparation, it performed oxidative phosphorylation. Racker and his colleagues took this result as evidence for identifying the inner membrane spheres with $F_{1}$; having previously identified ATPase with $F_{1}$, they now identified the spheres with ATPase. Although it took a number of years to more precisely determine the role of the other coupling factors and their physical realization in or near the inner membrane, this landmark 1965 report had succeeded in pushing the localization account to a lower level. That is, a particular enzyme, ATPase, was situated in the spheres that were such a visually prominent feature of the cristae. The spheres were the seat, not of electron transport, but of oxidative phosphorylation - the process that Green had largely dropped from consideration after his earliest work for lack of good traction on it. That left the inner membrane to which the spheres were attached as the only plausible localization site for the flavoproteins and cytochromes responsible for electron transport.

\section{Integrating Structure and Function}

The interfield excursions between cell biology and biochemistry in 1940 1965 were extraordinarily productive. In the early 1940s biochemists had a partial description of the biochemical mechanism for cellular respiration (Figure 1); cytologists had micrographs from light microscopes showing vague mitochondrial structures; and there were suspicions that these were related but little evidence and no interdisciplinary research area. A mere 20 years later there was an interfield theory relating a more detailed biochemical account ${ }^{51}$ to multiple morphological levels of the cell and its fine structure - as far down as $85 \AA$ spheres of ATPase on the cristae of the inner membrane of the mitochondrion.

51 For reviews of relevant research on biochemical mechanisms in the mitochondrion, see Lehninger, 1964; Scheffler, 1999; Wainio, 1970. 


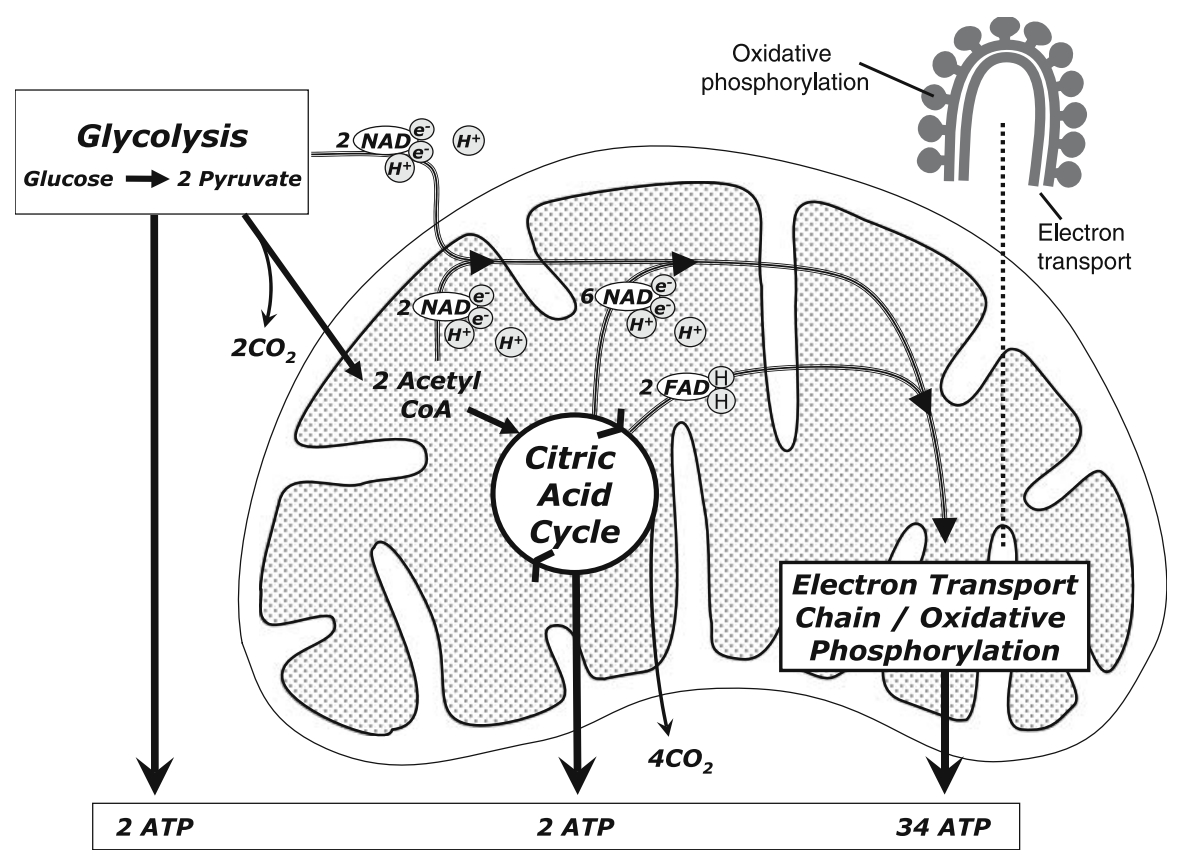

Figure 3 Functional decomposition of cellular respiration overlaid on a structural decomposition of the cell emphasizing the mitochondrion. Function-structure linkages are listed in temporal order: (1) Glycolysis: cytosol. (2) Citric acid cycle: mitochondrial matrix. (3) Electron transport: cristae. (4) Oxidative phosphorylation: ATPase (spheres on the cristae; see inset at upper right). Also shown is the initial transport of pairs of electrons $\left(\mathrm{e}^{-}\right)$with a proton $\left(\mathrm{H}^{+}\right)$and the number of ATP molecules synthesized per molecule of glucose. Not shown is fatty acid metabolism prior to the common pathway from acetyl CoA; this occurs in the mitochondrial matrix. Finally, each function of a cellular component is itself a mechanism at the biochemical level.

With components of the biochemical mechanism (particular enzymes or enzyme systems) successfully localized within components of the cell, those with a primary interest in the mitochondrial mechanism now had an integrated account of its structure and function. Much of this account is illustrated schematically in Figure 3 and is recapitulated here for three different levels of structural decomposition. ${ }^{52}$ Beginning at the most general structural level, the mitrochondrion became potentially more accessible to cytological investigation when a pioneering cell biologist (Claude) collaborated with electron microscopists (Porter and

52 There are subtleties in distinguishing levels that we have not pursued here. Parts at rather different size levels (e.g., protons and membranes) are at the same level with respect to a particular mechanistic account if their operations are coordinated within that account. See Craver and Bechtel, in press. 
Fullum) at Rockefeller to obtain the earliest electron micrographs of mitochondria in 1945. The biochemical research required to assign particular functions to mitochondria was undertaken by another team led by Claude at Rockefeller and extended by biochemists elsewhere. Specifically:

- The electron transport chain (represented by the succinoxidase and cytochrome oxidase enzyme systems) is localized in the mitochondrion by cell biologist Claude working with biochemists Hogeboom, Hotchkiss, and Schneider (1946-1948).

- Oxidative phosphorylation (and the electron transport chain) is localized in the mitochondrion independently by two biochemists, Green and Lehninger (1949-1951). As well, the pathways from pyruvic acid (Green) and fatty acids (Lehninger) through the citric acid cycle were localized there. ${ }^{53}$

- Glycolysis is localized in the cytoplasm by Lehninger (1949-1951); later it is further localized to the soluble portion, the cytosol, on the basis that the relevant enzymes are found in the final supernatant in cell fractionation. ${ }^{54}$ That is, glycolysis could be excluded from mitochondria or any other organelles characteristic of particulate fractions.

In 1952-1953, the structural decomposition proceeded down a level when cell biologists (Palade; also Sjöstrand) obtained micrographs showing cristae. Palade interpreted them as infoldings of an inner mitochondrial membrane and proposed a function for the new structure that was confirmed and extended by biochemists:

- Oxidative phosphorylation and the electron transport chain are more precisely localized in the cristae of the mitochondrion in studies of inner membrane fragments by Green and by Lehninger (1956-1958).

- The enzymes catalyzing the metabolism of fatty acids and the citric acid cycle are tentatively localized in the mitochondrial matrix, based on their exclusion from the cristae by Lehninger (1956-1958) as well as their solubility when mitochondria are fractionated (most remain in the supernatant) and their activity in solution. ${ }^{55}$

53 Lynen and Reichert, 1951; Stern, Ochoa and Lynen, 1952.

54 Reported in the textbook by Novikoff and Holtzman, 1970, p. 34.

55 Reported in the textbooks by Novikoff and Holtzman, 1970, pp. 35 and 105 (re solubility) and Lehninger, 1964, p. 63 (re activity in solution). 
In 1962, the structural decomposition proceeded down yet another level when cell biologist Fernández-Morán obtained micrographs clearly showing spherical structures protruding from the inner membrane:

- The enzyme ATPase is shown to catalyze oxidative phosphorylation (the reverse of hydrolysis of ADP) and is identified with the spheres on the cristae of the inner mitochondrial membrane by biochemist Racker (1960-1965).

With ATPase identified with inner membrane spheres, the structural and functional accounts had finally met at the molecular level. The interfield theory aligning these accounts at multiple levels exemplifies a key way in which structure matters. In numerous areas of science - not only cellular respiration and its relation to the mitochondrion - localizing the mechanisms that realize functions within the appropriate physical structures is an important interfield endeavor. ${ }^{56}$ However, there were some more particular, very provocative roles for structure in the case under examination. One involved the idea that membranes might hold certain molecules in place so as to facilitate certain chemical reactions, as in the "bucket brigade" notion of electron transport (eventually verified empirically).

Another, far more revolutionary role for structure came out of the attempts to understand oxidative phosphorylation. Prominent biochemists had tried since the mid-1940s to extend their successful accounts of what is now called substrate-level phosphorylation to oxidative phosphorylation and its coupling to electron transport. They proposed, and abandoned, a succession of phosphorylated chemical intermediates, ${ }^{57}$ not appreciating that localization of the reactions in or near the mitochondrial membrane might alter the problem. But Peter Mitchell, a maverick British biochemist, had spent years focusing on how membranes serve as (a) osmotic barriers and (b) potentially key contributors to the energetic process as the enzymes in them discharged protons and hydroxyl ions on different sides of the membrane. ${ }^{58}$ In

\footnotetext{
56 Darden and Maull, 1977.
}

57 See Allchin, 1997, 2002, for a probing analysis of the extended period during which no fewer than 16 different intermediates were proposed before the entire enterprise was finally seen to be misdirected. In particular, Allchin, 1997, p. 104 argued that for five of the proposed intermediates, 'the 'facts,' as originally perceived, were not false. But they did lose their intended status .... Evidence for these intermediates became irrelevant to ox-phos by becoming relevant to another causal process."

${ }^{58}$ See Prebble, 2001, for a discussion of how Mitchell developed his theoretical perspective. 
1961, he applied this thinking to the problem of oxidative phosphorylation and proposed that the reactions involved in electron transport served to generate a proton gradient across the inner mitochondrial membrane. As protons concentrated in the intermembrane space, the membrane blocked them from returning to the matrix except through the spatially directed channel of ATPase. The potential energy captured in the proton gradient drove ATP synthesis. ${ }^{59}$ Mitchell's proposal was initially extremely controversial, giving rise to what are often called the ox phos wars ${ }^{60}$ before being substantially incorporated into the accepted account of oxidative phosphorylation in the 1970s.

During the same period, researchers were achieving a molecular-level localization of components of the electron transport chain (including some newly-discovered ones) in the inner membrane. Just as Lehninger had expected in 1951, a set of such components ordered in the membrane near an ATPase molecule and associated coupling factors made up a respiratory assembly that had numerous repetitions along the lengthy, folded membrane. Thus, structure mattered in the mature integrated account in all three ways mentioned: (a) in the alignment with function that was achieved by localizing biochemical mechanisms in cellular components; (b) in the membrane's distinctive contribution in arranging macromolecules in an advantageous sequence; and (c) in the membrane's further, crucial role in oxidative phosphorylation.

\section{Interfield Theories}

We have highlighted a series of interfield excursions between cell biology and biochemistry in which investigators in each discipline supplied information or techniques that were useful to those in the other discipline. These excursions generated interfield theories in which systems detailed by biochemists were localized, and in some cases knit into, structures identified by cell biologists. Although they play an important role in science, interfield theories received little attention from philosophers until 1977, when Darden and Maull advanced them as an alternative to the theory-reduction model that was then prevalent.

Darden and Maull focused on how different fields could make distinct contributions to a larger understanding and did not seek to articulate a general framework of explanation. In recent years, though, philosophers analyzing the biological sciences (including Darden) have

59 Mitchell, 1961.

${ }^{60}$ See Prebble, 2002. 
identified a pattern of explanation which frequently involves interfield theorizing. Drawing upon biologists' own language of explaining phenomena by advancing accounts of the mechanisms responsible for them, these philosophers have sought to explicate mechanistic explanation. Although there are nuanced differences between various accounts, the central idea is that to explain a phenomenon, researchers identify the component parts and operations of the mechanism and how they are organized so as to realize that phenomenon. ${ }^{61}$

Casting the 25 years of interfield excursions as a series of investigations directed towards understanding and localizing the mechanisms of cellular respiration is not the only perspective that could be taken on this period, but is advantageous in placing the history in a framework that philosophers have found to have very widespread application. The primary insight is that, although much valuable information about a system can be acquired from detailed studies of its operation in situ, to explain how it is able to perform that activity requires taking it apart. In the case of cellular respiration, in situ studies could reveal such important factors as the rate of respiration when cells were exposed to various conditions. But to understand how cells capture the energy in substances like glucose and store it in substances like ATP required decomposing the cell structurally and the respiratory system functionally. Biochemists pursuing functional decomposition got an early jump on the process by developing procedures for isolating the component chemical reactions (operations) in certain enzyme systems and determining how they were organized. But their techniques could not inform them where in the cell the various operations were occurring and how that might affect the overall process. They did become aware that many of the responsible enzymes seemed to be bound into particles, a hindrance to their quest to isolate components and then resynthesize the whole system (the gold standard for a complete chemical account).

Whereas cytologists lacked the tools to identify structures at the relevant size and to make adequate contact with biochemistry, the pioneering cell biologists of the 1940s and 1950s brought powerful new tools to the enterprise. Specifically, cell fractionation enabled these investigators to decompose the cell into its constituent structures and electron microscopy enabled them to visualize the shape and organization of these structures. Fractionation in particular made possible collaborations with biochemists to determine which reactions were

${ }^{61}$ As characterized in Bechtel and Abrahamsen, 2005. For related analyses, see Bechtel and Richardson, 1993; Darden and Craver, 2002; Glennan, 1996, 2002; Machamer, Darden and Craver, 2000. 
located in which structures. Had this been the end of the story, the interfield excursion would have been brief, simply allowing a localization of function (cellular respiration) in a structure (the mitochondrion). But the fact that the responsible enzymes could not be brought into solution suggested more interesting results lay ahead.

Another important feature of mechanistic accounts is that often they are multi-level. The components of a mechanism are often themselves mechanisms which can again be subject to both structural and functional decomposition. Here the structural skills of the cell biologists took the lead, finding that mitochondria consisted of parts. The cristae were the first to be discovered and a decade later the spheres protruding from them. These discoveries help pose new questions for biochemists - were these parts responsible for different operations in the overall functioning of the mitochondrion? Their extant functional decomposition of respiration together with the tool of cell fractionation borrowed from cell biologists enabled them to situate some reactions in the cristae and others in the mitochondrial matrix. The discovery of spheres on the cristae prompted another round of attempts to relate chemical reactions to the new structure, and Racker's research demonstrated that the spheres could be identified with ATPase, the enzyme responsible for ATP synthesis. Despite the importance of this finding, how the energy released in oxidations was made available to drive ATP synthesis remained a mystery that did not yield to the usual biochemical strategies. The mystery was not solved until a biochemist with an unusual inclination to consider the role of membrane structure attacked the problem. With Mitchell's innovation, the mitochondrial membrane was not solely a location in which biochemical reactions were situated; it had itself become a working part of the mechanism. As the mechanistic framework is used to elucidate additional historical cases, it will become clearer whether structure often matters in ways that go beyond straightforward structure-function alignment at multiple levels.

\section{Acknowledgements}

We thank the editors and two anonymous referees for their extremely helpful suggestions on an earlier version of this paper. One referee proposed the term "interfield excursions," which well captured our intent. We are also most appreciative of insightful comments on the manuscript provided by Rita Anderson, Lindley Darden, and members of the DC History and Philosophy of Biology Group. 


\section{References}

Allchin, Douglas. 1997. "A Twentieth-century Phlogiston: Constructing Error and Differentiating Domains." Perspectives on Science 5: 81-127.

2002. "To Err and Win a Nobel Prize: Paul Boyer, ATP Synthase and the Emergence of Bioenergetics." Journal of the History of Biology 35: 149-172.

Altmann, Richard. 1890. Die Elementaroganismen und ihre Beziehungen zu den Zellen. Leipzig: von Veit.

Baldwin, Ernest. 1947. Dynamic Aspects of Biochemistry. Cambridge: Cambridge University Press.

Bechtel, William. 1984. "Reconceptualization and Interfield Connections: The Discovery of the Link between Vitamins and Coenzymes." Philosophy of Science 51: 265-292.

1986. "Building Interlevel Pathways: The Discovery of the Embden-Meyerhof Pathway and the Phosphate Cycle." J. Dorn and P. Weingartner (eds.), Foundations of Biology. Vienna: Holder-Picklert-Tempsky, pp. 65-97.

2006. Discovering Cell Mechanisms: The Creation of Modern Cell Biology. Cambridge: Cambridge University Press.

Bechtel, William and Abrahamsen, Adele. 2005. "Explanation: A Mechanist Alternative." Studies in History and Philosophy of Biological and Biomedical Sciences 36: 421-441.

Bechtel, William and Richardson, Robert C. 1993. Discovering Complexity: Decomposition and Localization as Strategies in Scientific Research. Princeton, NJ: Princeton University Press.

Benda, Carl. 1899. "Weitere Mitteilungen über die Mitochondria." Archiv für Anatomie und Physiologie (Physiologische Abteilung): 376-383.

Buchner, Eduard. 1897. "Alkoholische Gärung ohne Hefezellen (Vorläufige Mittheilung)." Berichte der deutschen chemischen Gesellschaft 30: 117-124.

Chance, Britton and Williams, G. R. 1956. "The respiratory chain and oxidative phosphorylation." Advances in Enzymology 17: 65-134.

Claude, Albert 1948. "Studies on Cells: Morphology, Chemical Constitution, and Distribution of Biochemical Functions." Harvey Lectures 43: 121-164.

Claude, Albert and Fullam, Ernest F. 1945. "An Electron Microscope Study of Isolated Mitochondria." Journal of Experimental Medicine 81: 51-61.

Craver, Carl and Bechtel, William. (In press). "Top-Down Causation without TopDown Causes." Biology and Philosophy.

Darden, Lindley and Craver, Carl. 2002. "Strategies in the Interfield Discovery of the Mechanism of Protein Synthesis." Studies in History and Philosophy of Biological and Biomedical Sciences 33: 1-28.

Darden, Lindley and Maull, Nancy. 1977. "Interfield Theories." Philosophy of Science 43: 44-64.

Embden, Gustav, Deuticke, H. J. and Kraft, G. 1933. "Über die intermediaren Vorgänge bei der Glykolyse in der Muskulatur." Klinische Wochenschrift 12: 213-215.

Fernández-Morán, Humberto. 1962. “Cell-membrane Ultrastructure: Low-temperature Electron Microscopy and X-ray Diffraction Studies of Lipoprotein Components in Lamellar Systems." Circulation 26: 1039-1065.

Fernández-Morán, Humberto, Oda, T., Blair, P. V. and Green, David E. 1964. "A Macromolecular Repeating Unit of Mitochondrial Structure and Function: 
Correlated Electron Microscopic and Biochemical Studies of Isolated Mitochondria and Submitochondrial Particles of Beef Heart Muscle." The Journal of Cell Biology 22: 63-100.

Fruton, Joseph S. 1972. Molecules and Life: Historical Essays on the Interplay of Chemistry and Biology. New York: Wiley Interscience.

Glennan, Stuart. 1996. "Mechanisms and the Nature of Causation." Erkenntnis 44: 5071.

Glennan, Stuart. 2002. "Rethinking Mechanistic Explanation.” Philosophy of Science 69: S342-S353.

Green, David E. 1951. "The Cyclophorase System." J. T. Edsall (ed.), Enzymes and Enzyme Systems. Cambridge, MA: Harvard University Press, pp. 17-46.

Hatefi, Youssef, Haavik, A. G. and Griffiths, David E. 1962. "Studies on the Electron Transfer System. XL. Preparation and properties of mitochondrial DPNH-coenzyme Q reductase." Journal of Biological Chemistry 237: 1676-1680.

—1957-1958. "Studies in Organized Enzyme Systems." Harvey Lectures 53: 177-227.

Hogeboom, George H., Claude, Albert and Hotchkiss, Rollin D. 1946. "The Distribution of Cytochrome Oxidase and Succinoxidase in the Cytoplasm of the Mammalian Liver Cell." Journal of Biological Chemistry 165: 615-629.

Hogeboom, George H., Schneider, Walter C. and Palade, George E. 1948. "Cytochemical Studies of Mammalian Tissues. I. Isolation of Intact Mitochondria from Rat Liver; Some Biochemical Properties of Mitochondria and Submicroscopic Particulate Matter." Journal of Biological Chemistry 172: 619-635.

Holmes, Frederic Lawrence. 1991. Hans Krebs: Vol. 1. The Formation of a Scientific Life 1900-1933. New York: Oxford University Press.

1992. Between Biology and Medicine: The Formation of Intermediary Metabolism. Berkeley, CA: Office for History of Science and Technology, University of California at Berkeley.

Kalckar, Herman M. 1974. "Origins of the Concept of Oxidative Phosphorylation." Molecular and Cellular Biochemistry 5: 55-62.

Keilin, David. 1925. "On Cytochrome, a Respiratory Pigment, Common to Animals, Yeast, and Higher Plants." Proceedings of the Royal Society B 98: 312-339.

1966. The History of Cell Respiration and Cytochrome. Cambridge: Cambridge University Press.

Keilin, David and Hartree, Edward F. 1939. "Cytochrome and Cytochrome Oxidase." Proceedings of the Royal Society B 127: 167-191.

Kennedy, Eugene P. and Lehninger, Albert L. 1949. "Oxidation of Fatty Acids and Tricarboxylic Acid Cycle Intermediaries By Isolated Rat Liver Mitochondria." Journal of Biological Chemistry 179: 957-972.

Kohler, Robert E. 1973. "The Background of Otto Warburg's Conception of the Atmungsferment." Journal of the History of Biology 6: 171-192.

-1973. "The Enzyme Theory and the Origin of Biochemistry." Isis 64: 181-196.

Krebs, Hans A. and Schmid, Roswitha. 1981. Otto Warburg: Cell Physiologist, Biochemist, and Eccentric. Oxford: Clarendon Press.

Krebs, Hans Adolf and Johnson, William Arthur. 1937. "The Role of Citric Acid in Intermediate Metabolism in Animal Tissues." Enzymologia 4: 148-156.

Lardy, Henry A. and Elvehjem, Conrad A. 1945. "Biological Oxidations and Reductions." Annual Review of Biochemistry 14: 1-30. 
Lehninger, Albert L. 1951. "The Organized Respiratory Activity of Isolated Rat-Liver Mitochondria." J. T. Edsall (ed.), Enzymes and Enzyme Systems. Cambridge, MA: Harvard University Press, pp. 1-14.

1964. The Mitochondrion: Molecular Basis of Structure and Function. New York: W. A. Benjamin, Inc.

Lehninger, Albert L., Wadkins, Charles L., Cooper, Cecil, Devlin, Thomas M. and Gamble, James L. Jr. 1958. "Oxidative Phosphorylation.” Science 128: 450-456.

Lipmann, Fritz. 1941. "Metabolic Generation and Utilization of Phosphate Bond Energy." Advances in Enzymology 1: 99-160.

Lynen, Feodor and Reichert, Ernestine. 1951. "Zur chemischen Struktur der 'aktivierten Essigsäure'." Angewandte Chemie 63: 47-48.

Machamer, Peter, Darden, Lindley and Craver, Carl. 2000. "Thinking About Mechanisms." Philosophy of Science 67: 1-25.

Meyerhof, Otto and Kiesslling, Wilhelm. 1936. "Über den Hauptweg der Milchsäurebildung in der Muskulatur." Biochemische Zeitschrift 263: 83-113.

Michaelis, Leonor. 1899. "Die vitale Färbung, eine Darstellungsmethode der Zellgranula." Archiv für mikrokopische Anatomie 55: 558-575.

Mitchell, Peter. 1961. "Coupling of Phosphorylation to Electron and Hydrogen Transfer By a Chemi-Osmotic Type of Mechanism." Nature 191: 144-148.

Novikoff, Alex B. and Holtzman, Eric. 1970. Cells and Organelles. New York: Holt, Rinehart, and Winston, Inc.

Ochoa, Severo. 1943. "Efficiency of Aerobic Phosphorylation in Cell-Free Heart Extracts." Journal of Biological Chemistry 151: 493-505.

Oppenheimer, Carl and Stern, Kurt G. 1939. Biological Oxidation. The Hague: W. Junk. Palade, George E. 1952. "The Fine Structure of Mitochondria." Anatomical Record 114: 427-451.

1952. "A Study of Fixation for Electron Microscopy." Journal of Experimental Medicine 9: 285-297.

Penefsky, Harvey S., Pullman, Maynard E., Datta, Anima and Racker, Efraim. 1960. "Partial Resolution of the Enzymes Catalyzing Oxidative Phosphorylation. II. Participation of a Soluble Adenosine Triphosphatase in Oxidative Phosphorylation." Journal of Biological Chemistry 235: 3330-3336.

Pflüger, Eduard. 1872. "Über die Diffusion des Sauerstoffs, den Ort und die Gesetze der Oxydationsprocesse im thierischen Organismus." Pflüger's Archiv für die gesammte Physiologie des Menschen und der Thiere 6: 43-64.

Porter, Keith R. and Blum, Joseph. 1953. "A Study in Microtomy for Electron Microscopy." The Anatomical Record 117: 685-707.

Porter, Keith R., Claude, Albert and Fullam, Ernest F. 1945. "A Study of Tissue Culture Cells by Electron Microscopy." Journal of Experimental Medicine 81: 233255.

Prebble, John. 2001. "The Philosophical Origins of Mitchell's Chemiosmotic Concepts: The Personal Factor in Scientific Theory Formulation." Journal of the History of Biology 34: 433-460.

2002. "Peter Mitchell and the Ox Phos Wars." Trends in Biochemical Sciences 27: 209-212.

Pullman, Maynard E., Penefsky, Harvey S., Datta, Anima and Racker, Efraim. 1960. "Partial Resolution of the Enzymes Catalyzing Oxidative Phosphorylation. I. Purification and Properties of Soluble Dinitrophenol-Stimulated Adenosine Triphosphatase." Journal of Biological Chemistry 235: 3322-3329. 
Racker, Efraim. 1965. Mechanisms in Bioenergetics. New York: Academic Press.

1968. "The Membrane of the Mitochondrion." Scientific American 218: 32-39.

Racker, Efraim, Tyler, D. D., Estabrook, Ronald W., Conover, Thomas E., Parsons, D. F. and Chance, Britton. 1965. "Correlations between Electron-Transport Activity, ATP-ase and Morphology of Submitochrondrial Particles." T. E. King, H. S. Mason and M. Morrison (eds.), Oxidases and Related Redox Systems. New York: Wiley, pp. 1077-1101.

Rasmussen, Nicolas. 1995. "Mitochondrial Structure and the Practice of Cell Biology in the 1950s." Journal of the History of Biology 28: 381-429.

1997. Picture Control: The Electron Microscope and the Transformation of Biology in America. Stanford, CA: Stanford University Press.

Rheinberger, Hans-Jörg. 1995. "From Microsomes to Ribosomes: 'Strategies' of 'Representation'." Journal of the History of Biology 28: 49-89.

-1997. Toward a History of Epistemic Things: Synthesizing Proteins in the Test Tube. Stanford, CA: Stanford University Press.

Scheffler, Immo E. 1999. Mitochondria. New York: Wiley-Liss.

Sjöstrand, Fritiof S. 1955. "The Ultrastructure of Mitochondria." In Fine Structure of Cells. Symposium held at the VIIIth Congress of Cell Biology. Leiden: Interscience Publishers, pp. 16-30.

Stern, Kurt G., Ochoa, Severo and Lynen, Feodor. 1952. "Enzymatic Synthesis of Citric Acid. V. Reactions of Acetyl Coenzyme A." Journal of Biological Chemistry 198: 313-321.

Thunberg, Torsten Ludvig. 1916. "Über die vitale Dehydrierung der Bernsteinsäure bei Abwesenheit von Sauerstoff." Zentralblatt für Physiologie 31: 91-93.

Wainio, W. W. 1970. The Mammalian Mitochondrial Respiratory Chain. New York: Academic.

Warburg, Otto Heinrich. 1925. "Iron, the Oxygen Carrier of the Respiration Ferment." Science 61: 575-582.

Warburg, Otto Heinrich and Christian, Walter. 1932. "Über ein neues Oxydationsferment und sein Absorptionsspektrum." Biochemische Zeitschrift 254: 438-458.

— 1936. "Pyridin, der wasserstoffübertragene Bestandteil von Gärungsfermenten." Biochemische Zeitschrift 287: 291-328.

_ 1938. "Bemerkung über gelbe Fermente.” Biochemische Zeitschrift 298: 368-377.

Wieland, Heinrich. 1913. "Über den Mechanismus der Oxydationsvorgänge." Berichte der deutschen chemischen Gesellschaft 46: 3327-3342.

Ziegler, Daniel M., Linnane Anthony W., Green, David E., Dass, C. M. S. and Ris, Hans. 1958. "Studies on the Electron Transport System: XI. Correlation of the Morphology and Enzymic Properties of Mitochondrial and Sub-Mitochondrial Particles." Biochimica et Biophysica Acta 28: 524-539. 